\title{
The triglossic relationship of Zezuru, Karanga and other Shona dialects in the speech and writing of Shona as a language in Zimbabwean primary schools
}

\author{
ChimhengaSylod, Dr Ester Chivhanga \\ Senior Lecturer, Centre for Student Management, Zimbabwe Open University, Zimbabwe \\ Principal Lecturer, United College of Education, Zimbabwe
}

\begin{abstract}
The research has endeavoured to highlight the problems of the triglossic relationship of Zezuru, Karanga and other Shona dialects in the speech and writing of Shona language in Zimbabwean schools. It focused on how Zezuru as a high variety Shona dialect has adversely affected the performance of learners writing 'O' level Shona examinations in Secondary school. The current Shona orthography lacks some sounds from other dialects and this makes it incapable of handling adoptives from other dialects and basing Shona writing on one dialect kills the other dialects and in turn the Shona language. The current Shona orthography based on two major dialects, that is Zezuru and Karanga, does not distinguish all the significant sounds that are distinguished by Ndau, Korekore, Manyika and Karanga and hence the Shona alphabet does not recognize and represent other speech forms of other Shona dialects. This linguistic situation coupled with orthographic problems causes low passes in Shona at 'O' level. Hence, one proposes, language awareness campaigns, use of Shona in the teaching of practical criticism and grammar and that the government gives value to other Shona dialects.
\end{abstract}

Keywords: Language planning, Triglossia, language policy, medium of instruction, African languages.

\section{Introduction and background to the study}

The focus for this study isto investigate the triglossic relationship among Zezuru, Karanga and other Shona dialects ( Ndau, Korekore and Manyika) in the speech and writing of Shona language in Zimbabwean schools. It focuses on how Zezuru as a high variety Shona dialect has adversely affected the writing of Shona as a language in Zimbabwean primary schools.

Shona language consists of Zezuru, Karanga, Manyika, Ndau and Korekore as dialects, which vary, in the number of distinctive speech sounds they use (Dube 2002). In Zimbabwean schools, the current Shona orthography in use is based on Zezuru dialect and does not represent significant sounds found in other Shona dialects. This has created limitations in the writing of Shona in Zimbabwean schools. The speakers of Shona dialects such as Karanga, Ndau and Manyika can be said to speak one form of Shona and use another form in writing. The current Shona orthography lacks some sounds from other dialects and this makes it incapable of handling adoptives from other dialects.

Zezuru is the Shona dialect that is accepted in the speech and writing of Shona language by Zimbabwean schools, publishers of Shona and the local media. It is the dominant dialect over Karanga and other Shona dialects in the Shona language examinations for Grade 7, ' $O$ ' \& ' $A$ ' level, University and Tertiary Institutions. Shona coursework textbooks used in schools are all based on Zezuru. ANdau or korekore who learns Shona at school with no Zezuru background has to work harder in Shona if he is to pass his Shona examinations. This is also confirmed by Chivhanga (2008) who concluded that the learners' performance in Shona language is influenced by the diglossic relationship between English and Shona languages or the dialects within Shona language. In the publishing industry, if a Shona writer writes wholly in one Shona dialect, which is not Zezuru, publishers will not publish it. The use of Zezuru guarantees a wider market. Linguistically this implies that the use of Zezuru is a powerful symbol in the development of Shona writings. Basing Shona writing on one dialect kills the other dialects and in turn the Shona language.

It is against this background that this study will investigate the problems of the triglossic relationship of Zezuru, Karanga and other Shona dialects in the speech and writing of Shona language in Zimbabwean secondaryschools.

The development of Shona orthography was based on Zezuru dialect and to some extent Karanga dialect. (Dube 2002). It is not representative of all Shona dialects. In Zimbabwean schools the writing and reading of Shona language based on Zezuru dialect has compromised heavily on the expression and creativity of other dialects. (Dube 2002: 97). School children who are speakers of other dialects other than Zezuru develop inferiority complex towards their dialects. They see Zezuru as a superior high variety dialect that negatively influences the existence of other dialects such as Manyika, Ndau and Korekore. The inadequate representation 
of these dialects in Shona orthography has created a triglossic relationship of Zezuru, Karanga and other Shona dialects in which Zezuru as a high variety influences the development of other Shona dialects. In the development of Shona orthography Zezuru is the dialect of high variety while Karanga is of low variety but also higher than the other Shona dialects. Zezuru has influenced the development of spellings and meanings of words from other Shona dialects. Learners from other Shona dialects may be disadvantaged in the speech, creation and writing of words that have similar meanings to those of Zezuru. This may adversely affect the development of a rich Shona language in Zimbabwean primary schools.

The current Shona orthography based on two major dialects, that is Zezuru and Karanga, does not distinguish all the significant sounds that are distinguished by Ndau, Korekore, Manyika and Karanga and hence the Shona alphabet does not recognize and represent other speech forms of other Shona dialects. It does not distinguish between $/ \mathrm{v} /$ and $/ \mathrm{w} /$ as in mugovera - 'Saturday' and mugowera - 'Saturday' respectively. On the other hand, the Karanga use fricatives as in 'zhara'- poverty whereas other dialects use affricates as in 'nzara'poverty. In writing the Karanga use Zezuru dialect (nzira) and in speech they use Karanga (zhira). According to Dube (2002:2) "the voiced alveolar /1/ as in Ndau names such as 'Sithole' and 'Dhliwayo' and consonant clusters are not accommodated in the current Shona orthography". Such shortcomings confuse the learners of Shona language in Zimbabwe schools who are forced to have two Shona languages, one for writing (Zezuru) and another one for speech (other Shona dialects).

One noticeable problem is that children from areas where Zezuru is not their dialect may be adversely affected in their performance in the Shona language examinations of Grade 7, in Zimbabwean schools. Those from other Shona dialects have seen their dialects as inferior and of low variety than the Zezuru and Karanga. They work under unfavorable conditions, which forces them to think in their own dialect and write in Zezuru. They have to create time to learn Zezuru and to them learning Shona at school is like learning a second language.

The Shona textbooks mainly used in schools from primary to university levels are all dominated by the Zezuru dialect. The local media such as the Zimbabwe Broadcasting Television and newspapers use Zezuru and maybe Karanga dialects in speech and written word of Shona language. This has left the other Shona dialects being underdeveloped and inadequate to be used for National examinations of Shona language such as those of Grade 7. Learners are forced to use Zezuru/ Karanga even if they would want to use their dialect in situations where their dialect would be more appropriate in equivalent terms. This may affect their performance in answering questions for Shona language examinations in Zimbabwean primary schools.

\section{The statement of the problem}

The focus for this study is to investigate the triglossic relationship of Zezuru, Karanga and other Shona dialects ( Ndau, Korekore and Manyika) in the speech and writing of Shona language in Zimbabwean schools. It seeks to answer the following question: "How does the triglossic relationship of Zezuru, Karanga and other Shona dialects affect the performance of learners in the speech and writing of Shona as a languagein Zimbabwean primary schools?

\section{Objectives if the study}

- To suggest solutions to the problems of the triglossic relationship of Zezuru, Karanga and other Shona dialects in the teaching and learning situation of Shona language in Zimbabwean schools.

- To suggest ways in which Shona language could be developed in order to encompass all the Shona dialects in the speech and writing of Shona language examinations in Zimbabwean schools.

\section{Theoretical Framework.}

The term triglossia was derived from diglossia. It is a double overlapping diglossia as argued by AdulazizMkilif (1978) when he described it as a situation of intersection between two developing diglossia situations as in Tanzania where Swahili and some vernacular and the other involving Swahili and English. Triglossia involves one language or code as the ultimate high variety, another as an intermediate high-low variety and others become the low varieties. For example English is the high variety, being used for official government business, commercial and legal transactions, and in higher education. In urban areas, Swahili is the low variety, being the first language for children and the medium of instruction in primary schools and in all conversation with family members and friends. In rural areas, however, Swahili is the high variety and the local vernacular languages the low varieties. This triglossic language situation enhanced the status of president Nyerere as a leader because this enabled him to negotiate with the British yet Swahili enabled him to communicate widely with his own people. Swahili was designated a national language and other indigenous languages were relegated to vernacular.

In Zimbabwe Shonahas a triglossia involving its dialects Zezuru, Karanga and other dialect e.g. Ndau. This can be demonstrated using the model below. 
Fig. 1 The triglossic relationship of Zezuru, Karanga and Ndau

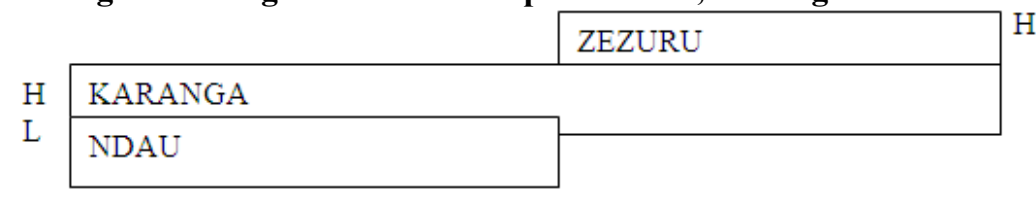

Zezuru is the ultimate high variety dialect as far as advancing the interest of the Shona speakers in Zimbabwe is concerned, Karanga, from Fig 1 above is the intermediate high- low variety and Ndau is the low variety. According to Chiwome (1992:87) and Dube (2002) Zezuru is a high variety dialect of Shona that is being used for official government business and in higher education. Examinations questions for Grade 7 level in Shona as a language are written in Zezuru. Zezuru is the primary dialect that is used in the teaching and writing of Shona. It is the medium of instruction in the teaching and learning of Shona in Zimbabwean schools either from the beginning or after the other Shona dialects have been used in the first three grades of the primary school.

The introduction of Zezuru dialect as a base for Shona orthography by Doke is typical of the acquisition of a high variety. In terms of societal influence Zezuru has spread far beyond its original boundaries of the Shona speaking people. In Shona, Zezuru is seen as a dialect of prestige and power while other dialects such as Korekore, Ndau and Manyika are maintained as solidarity codes. It is also the vehicle for access to the publishing of Shona language literature (Chivhanga 2008). In formal settings such as schools Karanga is an intermediate high-low variety. It is low to Zezuru dialect but also high to other Shona dialects such as Ndau and Manyika especially in rural areas where local dialects are in use. In other words Karanga is the high variety dialect with respect to Ndau, Korekore and Manyika.

Fromkin and Rodman (1983:245) define the dialects of a single language as mutually intelligible forms of that language that differ in systematic ways from each other. It is the variation of a spoken language shared by those in a particular area or a particular social group or both. These are varieties which are grammatically as well as phonologically different from other varieties (Chambers and Trudgill 1984:5). In general a dialect is a variety of a language spoken by a group of people united by geographic, social, ethnic, historical, psychological or other factors. It differs from other dialects/ varieties in pronunciation, vocabulary and grammar. Shona as a Bantu language consists of Zezuru, Karanga, Manyika, Ndau and Korekore dialects.

According to Oxford Companion to the English Language (1992:730) orthography is a term for correct or accepted writing and spelling and for a normative set of conventions for writing and spellings. In other words it is the art of spelling words according to accepted usage. A good orthography should present all and only the significant sound in a language (Bamgbose 1965:1). The current Shona orthography lacks some sounds that would make it impossible to write some technical terms in Shona.

\section{Review of the literature}

The researcher considered a review of the literature on the triglossic relationship of Zezuru, Karanga and Ndau in the speech and writing of Shona language in Zimbabwean schools in order to place the study in its proper context.

In Zimbabwe, Dube (1997) researched on the diglossic relationship between Shona and English in the post- independence era and Chivhanga (2008) researched on the diglossic relationship between Shona and English languages in the teaching and learning situation in Zimbabwean schools. Their findings show that Shona in its present form is inadequate as a language of instruction, and in dealing with labour laws and government policies. This conclusion did not show that the unification of Shona dialects by Doke (1931) created a triglossic relationship of Zezuru, Karanga and other dialects that resulted in orthographic problems in the speech and writing of Shona as a language. It is in the interest of this background that this study focus on the problems of the triglossic relationship of Zezuru, Karanga and other Shona dialects in the speech and writing of Shona as a language in Zimbabwean in primary schools.

Dube (1997) and Chivhanga (2008) also confirmed that Shona people have negative attitudes towards their language. This conclusion did not focus on the attitudes specifically for the learners and teachers who are sidelined because of their dialect background in the classroom situation. Dube (2002:99) in her research on Shona orthography concluded that the current Shona orthography is one of the causes of negative attitudes towards Shona by some Shona speakers because it sidelines their dialects. This study will move away from Chivhanga (2008) and Dube (1997)'s focus in that it will try to find out whether these attitudes by Shona language learners are as a result of the triglossic relationship of Zezuru, Karanga and other Shona dialects and may lead to the poor performance by learners of Shona language at Grade 7 level in Zimbabwean primary schools.

In her research, Dube (2002) concluded that Shona orthography based on one dialect, Zezuru, works against the development of the language itself. It compromises heavily on the expression and creativity of other 
dialects. In other words if some speech sounds are not found in Zezuru it would disadvantage other dialects that are found in Shona as a language. In his phonetic analysis of the Shona dialects, Doke (1931) selected Zezuru as the norm and this propelled it to the position of prominence and prestige in the designing of Shona orthography. This research seeks to find out ways in which Shona orthography can be developed in order to encompass the speech sounds other Shona dialects.

\section{The unification of Shona dialects and the development of Shona orthography in Zimbabwe}

In Zimbabwe there are six main groups of Shona dialects, the first five in the Central, North and East of the country all mutually intelligible, the sixth in the West and South West of the country has developed some divergent and peculiar characteristics of its own and is not readily understood by the speakers of the Central, Northern and Eastern dialects (Chimhundu 1992). The Central dialects of Shona are classified as Zezuru, Karanga and Manyika and the Northern and Eastern as Korekore and Ndau. The Western and South Western dialects are known as Kalanga.

The Unified Shona orthography has undergone tremendous changes since 1931 till 1967. The first was done by Doke in 1931, the second in 1955 and the current one was established in 1967.

The arrival of missionaries in the 16th Century in Zimbabwe saw the beginning of the writing of Shona language in different dialects. These missionaries set different missions in different areas of Zimbabwe. According to Dube (2002:8) and Chivhanga (2008) the initial writing in Shona in its various forms was done by different missionary societies in areas where Shona dialects were spoken. These missionaries had a lot of enthusiasm but little or no expertise in linguistic description. This created problems of orthographic differences within the same language, such as difference in choice of letters to mark sound spellings, word divisions and word choices. According to Kahari (1986:86) research into the nature and structure of the various dialects was conducted rather haphazardly at denominational levels by different missionaries. Men and woman who were involved in the study of these dialects worked independently and often without cooperation and coordination. Representations of the different missions, having failed in their own attempt to develop a common system of writing Shona, commissioned the South African linguist C M Doke, to undertake a dialect survey in 1929 and make suggestions about a common writing system. (Chimhundu 1992). In other words the purpose of his visit was to make a thorough survey of the language position throughout the country with a view to advising the Government upon a uniform orthography and a possible unification of dialects, for the standardization of an official language for that part of the country inhabited by the Shona speaking people. Chimhundu (1992) argued that Doke posited six different dialect groups of the language that he coined 'Shona' consisting of Korekore, Zezuru, Manyika, Ndau, Karanga and Kalanga, Doke's committee composed of representatives from some but not all dialects involved. Korekore and Kalanga were not represented at all. The same person represented Manyika and Ndau. Such representation had two major consequences: when differences in vocabulary occurred the commission relied most heavily on Zezuru and to a lesser extent on Karanga and Kalanga was completely ignored (http://www.msu.edu//dwyer/LgDialPr.htm). Research into the structure of Kalanga showed that it was phonetically different from other dialects (Kahari 1986: 88). For this reason and because Kalanga has a somewhat divergent vocabulary, Doke did not see his way clear to recommend that it be included with other language groups which showed common phonetic as well as grammatical features.

According to Chimhundu (1992), Dube (2002:19) and Chivhanga (2008) Doke's work on Shona orthography was based on the Memorandum on Orthography put by the International Institute of African Languages and Cultures which used the International Phonetic Alphabet. From this, as a basis of comparison and for the main phonetic analysis, Doke chose Zezuru as the main dialect to be used in the Shona orthography for three reasons ( Doke 1931).

- Zezuru included every phonetic phenomenon that would be necessary to consider in the alphabet for the unified Shona.

- Zezuru pronunciation was remarkably uniform and showed no variations over the area was used.

- Zezuru stood in a central position visa-vise the other groups and it presented a greater variety in the speech sounds used than the other dialects and so was better fitted than others to serve as the basis for a common alphabet.

Zezuru became the dominant dialect to be used in Standard Shona. It influenced the development of other dialects. According to Doke (1931) a unified grammar for Shona was to be standardized on the basis of Zezuru and Karanga and that The Korekore forms of noun prefix i.e. hu or xu should be ignored in a unified grammar. Publishers and writers based their literature on the Shona spoken in the center of the country. The first writers of Shona appeared to be Zezuru, and others who were not, received their education and professional training in institutions in the center of the country where teachers and other professional people like nurses, the few doctors, lawyers and the clergy spoke a common form of Shona based on the center of the country which was fundamentally Zezuru. Zezuru became a language with prestige and a powerful symbol in the development 
of Shona writing because it is the dialect of the center and is spoken and written by the growing class of educated and influential people.

According to Chimhundu (1992:100) the missionaries did not have the necessary linguistic or phonetic training and this resulted in a divergent system of spelling because wrong associations were made between sound and symbol and making reference only to Roman letters. The spelling system that Doke adopted was based on the speech sounds found in Zezuru dialect and ignored other dialects. This gave Zezuru a lot of prominence. The domination of Zezuru dialect in the Shona orthography created further confusion when Doke(1931) imposed the disjunctive system of word division which was based on rough translations of individual Shona morphemes. Chivhanga (2008) pointed out that the early missionaries were guided by elements of meaning rather than by Shona phonological rules and failed to recognize that Shona word division is marked by penultimate length or relative prominence of the last but one syllable in each word. After the unification of Shona dialects translations of the of the New Testament from English to Shona was based on Zezuru and this probably set the basis adopted for further work in Standard Shona.

In preparation for the unification of Shona dialects Doke (1931) proposed that a dictionary of Shona be prepared to be as inclusive as possible of words from Zezuru, Karanga, Manyika and Ndau and that words from Korekore be admitted sparingly. He also recommended that Kalanga or Western Shona should not be included in the unified Shona.

Professor Doke (1931) made the first major move in the creation of a unified Shona orthography that was approved for schools. All the churches in their publications, including the Bible that appeared in this orthography in 1945, adopted his proposals. A further step was taken in 1955 when a standard orthography limited to letters and letter combinations of the Roman alphabet, but based on the same rules of word division of 1931 system was approved for use by the Government for all departments of government and was adopted by the press. The subsequent revisions of the orthography in 1955 and 1967 left the basic Dokean system intact.

Mkanganwi (1975) argues that by leaving out tone markings the designers of 1967 orthography failed to meet their aim of drawing up an alphabet that would reflect all phoneme contrasts of Shona. They only differentiated consonants and vowel systems. Fortune (1972: 21) argued that the designers of the 1967 orthography wanted to make the Shona alphabet like English and limited the alphabet far too much. Apart from leaving out the special sounds in some dialects other than Zezuru e.g. Manyika do not distinguish between /v/ and /w/. In Standard Shona spelling Manyika and Ndau dialects were to follow Zezuru and Karanga. According to Dube (2002:12) the current Shona orthography does not distinguish all the significant sounds which are distinguished by Manyika, Ndau ,Korekore and Karanga. The speakers of these dialects can be said to speak one form of Shona and write another. The written Shona (Zezuru) does not represent significant sounds found in other dialects of Shona and this shows that the Shona alphabet does not recognize and represent the other speech forms of other Shona dialects.

Doke based his system of spelling on the speech sounds found in Zezuru dialect and this has created problems for other dialects and the 1967 orthography designers did not consider this shortcoming. Chimhundu (1992:80) argued that Zezuru which Doke had chosen as the norm for phonetic analysis gained prominence at the expense of other Shona dialects. In other words Zezuru is the dialect of prestige and power which has influenced the writing of ' $\mathrm{O}$ ' and ' $\mathrm{A}$ ' level examinations of Shona.

\section{Methodology}

In order to carry out this research, informal observations were made. Questionnaires to collect data from the Shona teachers and pupils in secondary schools in Midlands's province were used to collect data. The questionnaires were administered to 150 secondary school learners with different Shona dialect background doing ' $\mathrm{O}$ ' and 'A' Level Shona in Midlands province and to 50 teachers who are teaching Shona at secondary school level and other tertiary institutions. The sample provided enough information to generalise on the Zimbabwean schools population.

Interviews with selected Shona writers and publishers from different backgrounds of Shona dialects were carried out to find out how Shona language can be developed infusing all the dialects of Shona. The study involved literature study, which include an overview of relevant published and unpublished dissertations; local sources e.g. newspapers, theses, books and research periodicals at a national and international level. Current researched documents in published and unpublished dissertations provided information into the problems of the triglossic relationship of Zezuru, Karanga and other Shona dialects in the speech and writing of Shona in Zimbabwe schools. Shona language examination reports from Chief examiners was analysed and used in this research.

\section{Research Findings}

Findings show that problems of Shona spellings are as a result of the difference between dialects of the spoken Shona language and the written one. In speech the students are free to use different dialects but in the written 
Shona language standard orthography requires them to use the Zezuru dialect. It is this difference that caused the spelling problem among my students doing Shona at 'O' level.

The aim of this study was to find out information on whether the students' dialects could contribute to their failure to spell Shona words or could bring problems in their understanding of word division rules. The respondents noted that they had problems of sounds when reading or writing in Shona. The current Shona orthography does not accommodate some word sounds found in Shona, as in, for example, 'kamba' (tortoise) and 'kamba' (a small hut) as argued by (Mberi 2006). One major problem that was frequent in the responses was that many students mixed dialects when writing and this made the composition marking very difficult. In some cases the teacher had to consult other teachers on what to mark correct or wrong. Sometimes the students' dialects and that of the texts differed resulting in students failing to answer Shona ' $O$ ' level questions correctly. Some teachers pointed out that one of their problems was the failure by students to express themselves and understand texts because of different dialects found in the texts and that which they use in their day to day speech. As a result of different dialects in Shona the students are forced to resort to English as a means of communication even during Shona lessons. In the teaching of some Shona words with the same spelling but different meanings used in different dialects such as 'kunyara'(to be ashamed) in Zezuru and 'kunyara'( to be tired) as in Karanga the students became confused in answering comprehension questions which involved such words. This implies that there is need to have a common standard Shona orthography that is inclusive of all the Shona dialects. This will alleviate problems being faced by teachers when marking compositions and thus improve the performance of students when answering Shona ' $\mathrm{O}$ ' level examination questions.

The interviewees felt that Zezuru dialect is influencing the performance of Shona candidates answering Shona ' $\mathrm{O}$ ' level examination questions. The main reason given is that teachers resort to Zezuru terms when teaching some aspects of Shona because the Shona terms for other dialects are not included in the standard Shona orthography. Reference materials being used in secondary schools or even at University level in teaching Shona grammar and practical criticism are in Zezuru. This is supported by Viriri (2003) who pointed out that Zezuru continues to dominate Zimbabwe's social economic and educational life in the teaching of Shona.

Some interviewees encountered problems in spellings and word division during their teaching experience in secondary schools. Word division in Shona is an area of orthography that has created problems for teachers and students in the teaching and learning situation in Shona. Most of the interviewees agreed that it was difficult to grasp the rules of Shona word division. Those who mastered these rules did so after a struggle. They argued that Shona orthography has contributed to the confusion in Shona spellings by some students. They noted that the orthography does not include some other dialects e.g. Korekore and Ndau. This has led the students to spell certain words wrongly as in "mpan'ombe" or " mupamombe'(one who has given cattle).

\section{Conclusions}

The Shona students, teachers, lecturers and Shona writers agree that Shona is underdeveloped and this hinders its use in such areas as teaching and learning in secondary schools. This has forced the Shona teachers and learners to useZezuru where it would have been to their advantage to use other Shona dialects. In their research Chiwome and Thondhlana(1992) also concluded that some educators still use English to teach African languages such as Shona because they do not have the academic jargon for the different dialects or register for the concepts they teach. Shona does not have vocabulary for use in other Shona dialects or academic discourse and areas such as phonetics, phonology, morphology, syntax, and theories of literature do not have standardized Shona terminology that include other Shona dialects with which they can be taught.

The use of Zezurudialect in the teaching of Shona is one reason why the learners are failing to answer well ' $\mathrm{O}$ ' level Shona grammar examination questions. It has been found that Shona dialects in their present form are inadequate to be used as medium of instruction. This has been confirmed by the interviewed examiners, writers and lecturers who pointed out that Zezuruas a high variety dialect adversely affects the performance of learners writing ' $\mathrm{O}$ ' level Shona examinations in secondary schools in Zimbabwe. The Shona students, teachers, lecturers and Shona writers agree that Shona is underdeveloped and this hinders its use in such areas as teaching and learning in secondary schools. It does not have vocabulary for use in academic discourse and areas such as phonetics, phonology, morphology, syntax, and theories of literature do not have standardized Shona terminology with which they can be taught.

The research also revealed that the learners' failure to answer Shona ' $O$ ' level examination questions well was not only a result of the influence ofZezuru in it's diglossic relationship with other Shona dialects but a result of the short comings of the current Shonaorthography. The respondents noted that the learners had problems with sounds whenreading and writing Shona. The current Shona orthography does not accommodate wordsounds found in Shona. There is need to have further investigations on this issue. Anotherproblem of the current Shona orthography is that it does not include all the major dialectsof Shona. Sometimes the learners' dialects differed from that of the Shona texts and thiscaused confusion and failure to understand the questions being asked in Shona ' $\mathrm{O}$ ' levelexaminations. 


\section{References}

[1]. AbdulazizMkilifi M. H. 1978 Triglossia and Swahili-English Bilingualism in Tanzania. In Fishman 1978: 129-152

[2]. Bamgbose, A. 1991. Language and the Nation: The language question in sub- saharan Africa. Edinburg: Edinburg University Press.

[3]. Chambers, J. K. and Trudgill, P 1984. Dialectology, Cambridge: Cambridge University Press Chimhundu, H. 1992.

[4]. 'Standard Shona Myth and Reality' in Democratically speaking International Perspectives on language Planning, Vigel, T. Crawhall (editor). National Language Project, Salt River. 7924. Republic of South Africa. SAPEM,October 1993, 57-59.

[5]. Chivhanga, E. 2008 Thediglossic relationship between Shona and English languages in Zimbabwean secondary schools.Pretoria: Unisa.

[6]. Chiwome, E. M. 1992. A social History of the Shona Novel.Effel Flats: Juta Zimbabwe Pvt Ltd.

[7]. Doke, C. M. 1931.A comparative study in Shona phonetics, Jahannesburg: Wits Univesity Press.

[8]. Dube, S. 1997.A study into reasons why Shona as the low variety in a diglossic relationship with English in post-independent Zimbabwe.Unpublished Article submitted to the Department of African Languages and Literature at Unisa.

[9]. Dube , S. 2002An investigation of the current Shona orthography: effects of its limitations and suggested solutions. Unpublished dissertation for MA, Pretoria : University of South Africa.

[10]. Fromkin, V. and Rodman, R. 1983 An introduction to language. CBS: Colege Publishing

[11]. Kahari, G 1986Aspects of the Shona Novel. Gweru: Mambo Press

[12]. Viriri,V. 2003. 'Language planning: the conservation and management of indigenous languages in Zimbabwe.'Paper presented at ICOMOS 14th General Assembly and Scientific Symposium 